\title{
The developing Canadian Integrated Ocean Observing System (CIOOS)
}

\author{
Lenore Bajona $\ddagger$ \\ ‡ Ocean Tracking Network (OTN), Halifax, Canada
}

Corresponding author: Lenore Bajona (lenore.bajona@dal.ca)

Received: 18 Aug 2017 | Published: 20 Aug 2017

Citation: Bajona L (2017) The developing Canadian Integrated Ocean Observing System (CIOOS). Proceedings of TDWG 1: e20432. https://doi.org/10.3897/tdwgproceedings.1.20432

\begin{abstract}
Canada's ocean science community which includes the federal government, academia, small businesses, not-for-profit organizations, and other research partners, collect and synthesize physical, chemical and biological ocean observations. This information is used for discovery research purposes, to model ocean changes and provide environmental assessment advice, support resource management decision-making, and establish baseline data for long-term monitoring.

Canada's ocean community collects large amounts of data but, aside from building comprehensive ocean observatories (Fisheries and Oceans Canada (DFO) et al. 2010), there is no easy mechanism to integrate data from various sources to allow the exploration of interrelationships among variables, and no coordination and collaboration mechanism for the ocean community as a whole to generate an efficient system (Ocean Science and Technology Partnership (OSTP) and for Fisheries and Oceans Canada (DFO) 2011). Consequently, we observe fragmented and isolated data - which may never be used outside of a specific project because it is not discoverable by other potential end users. Canada's ocean science community (Wallace et al. 2014), led and supported by Fisheries and Oceans Canada (DFO), is advancing the development of a Canadian Integrated Ocean Observation System (CIOOS) that brings together and leverages existing Canadian and international ocean observation data into a federated data system which will generate value for users. This integrated ocean observing system (Wilson et al. 2016) will improve coordination and collaboration among diverse data producers, improve access to
\end{abstract}


information for decision making, and enable discovery and access to data to support a wide variety of applied and theoretical research efforts to better understand, monitor, and manage activities in Canada's oceans.

Conceptual discussions on CIOOS have taken place with Environment and Climate Change Canada, Natural Resources Canada, the Department of National Defence, DFO, and the academic and NGO sector. Work is underway on four closely-linked projects to move CIOOS from the concept stage to the design stage, covering key areas required to develop a robust and integrated observing system:

1. Governance;

2. Data and observations;

3. Cyber Infrastructure; and,

4. Visualization tools.

The project teams are evaluating the current ocean observing landscape in Canada (what exists, who has it, and what state is it in), the standards followed, and the gaps, limits or barriers to setting up an integrated ocean observing system. From this they will develop a list of recommendations to support the implementation of $\mathrm{ClOOS}$, which will include which standards to use, the resources required (FTE, capital investment, capabilities), and the best practices to follow.

\section{Keywords}

data management, data handling, data interoperability, metadata, data discovery, biological monitoring, species occurrence, environmental data, ecosystem data, telemetry data, data standardization, oceanographic data, integrated oceanographic data system, ocean observations

\section{Presenting author}

Lenore Bajona on behalf CIOOS Task Team and associated project team participants

\section{References}

- $\quad$ Fisheries and Oceans Canada (DFO), Ocean Science and Technology Partnership (OSTP), with the financial support of the Canadian Space Agency (CSA) (2010) Canadian Survey of Atlantic, Pacific, Arctic and Great Lakes Observing Systems. http:// www.qc.dfo-mpo.gc.ca/publications/science/enquete-survey-eng.html

- $\quad$ Ocean Science and Technology Partnership (OSTP), for Fisheries and Oceans Canada (DFO) (2011) Lessons Learned from OOS in Canada: Preliminary Assessment of OOS Value. http://www.qc.dfo-mpo.gc.ca/publications/science/documents/Preliminary\% 2000S\%20value\%20assessment e.pdf 
- Wallace DR, De Young B, Iverson S, Laroche J, Whoriskey F, Archambault P, Davidson F, Gilbert D, Greenan B, Pepin P, Johnson C, Hebert D, Hanlon J, Rysgaard S, Carter BL, Gillespie R, House D, Snelgrove P, Myers P, Babin M, Holthus P, Rae A (2014) A Canadian contribution to an Integrated Atlantic Ocean Observing System (IAOOS). In: Presented at the IEEE/OES Marine Technology Society OCEANS 2014 St. John's, Newfoundland. Conference Paper published in the conference proceedings, 14-19 September 2014. https://doi.org/10.1109/OCEANS.2014.7003244

- Wilson L, Smit M, Wallace DWR (2016) (Towards a Unified Vision for Ocean Data Management in Canada: Results of an Expert Forum). In: SciDataCon 2016: Advancing the Frontiers of Data in Research Proceedings from SciDataCon 2016: Advancing the Frontiers of Data in Research. 